\title{
Effect of Formaldehyde Exposure on Oxidative Stress Markers, Liver and Kidneys of Medical Students during Dissection in Gross Anatomy Laboratory
}

\author{
Michael Chinedu Olisah ${ }^{1, *}$, Samuel C. Meludu ${ }^{2}$ and Dioka C.E. ${ }^{3}$ \\ ${ }^{1}$ Department of Medical Biochemistry, Chukwuemeka Odumegwu Ojukwu University, Uli, Anambra State, \\ Nigeria. \\ ${ }^{2}$ Department of Human Biochemistry, Nnamdi Azikiwe University, Nnewi Campus, Anambra State, Nigeria. \\ ${ }^{3}$ Deparment of Chemical Pathology, Nnamdi Azikiwe University, Nnewi Campus, Anambra State, Nigeria.
}

*Corresponding author e-mail- olisemike2007@yahoo.com; Tel: +234(0)8038884404

\begin{abstract}
Background: Medical students are routinely exposed to formaldehyde during their dissecting practical classes and human exposure to formaldehyde is associated with multiple adverse effects. Chronic exposures may cause oxidative stress and may result in some vital organ damage.

Materials/Methods: The study included the total class population of the 2017 set of medical students (56 male students) from College of Medicine, Chukwuemeka Odumegwu Ojukwu University, Uli. These students were recruited immediately after first year, that is, before the commencement of dissection. Baseline samples were collected before exposure to formaldehyde. Subsequent samples were collected at one month, three and six-month intervals. All samples were collected immediately after dissection at the required period. The dissection periods are two times per week each lasting for 3 hours (1-4 pm). Eight millilitres $(8 \mathrm{ml})$ of fasting blood samples were collected from all subjects by sterile disposable syringes into a sterile plain container and allowed to clot, retracted and centrifuge at $3000 \mathrm{rpm}$ for 10 minutes. Thereafter, serum was separated into two aliquots. One part of the samples were stored at $-20{ }^{\circ} \mathrm{C}$ for analysis of oxidative stress markers $(\mathrm{GPx}$, SOD and MDA) within two weeks of collection, while the remaining aliquot was stored at $-20{ }^{\circ} \mathrm{C}$ and used for the analysis of liver and kidney markers. Data obtained was analyzed using SPSS version 2021.

Results: Glutathione peroxidase and superoxide dismutase (SOD) activities were significantly reduced after one and three-month periodic exposures when compared with the baseline study. Malondialdehyde (MDA) level was significantly lower when the baseline study was compared with the one month and three-month exposure but does not differ significantly from that of six-month exposures. The activity of ALT was significantly higher after one and three-month periodic exposures when compared with the baseline study. However, when the baseline study was compared with six-month exposures, it was not significant. When the activities of AST, ALP and other liver markers which include albumin, AFP, total protein, conjugated and unconjugated bilirubin of baseline study were compared with the one, three and six-month periodic exposures, it was not statistically significant across all groups. When the concentrations of the serum electrolytes of the baseline study were compared with one, three and six-month periodic exposures, it was not statistically significant. However, the concentration of urea was found to be significant when one-month periodic exposures were compared with the baseline study.

Conclusion: Formaldehyde exposures during medical training may not cause significant damage to tissues. Apart from the irritation of the eyes, upper airways and skin, there is no clear evidence that formaldehyde induces cellular damage in the vital organs of the students within the short period of exposures
\end{abstract}

Keywords: Formaldehyde, Kidney failure, Electrolytes, Cystatin C.

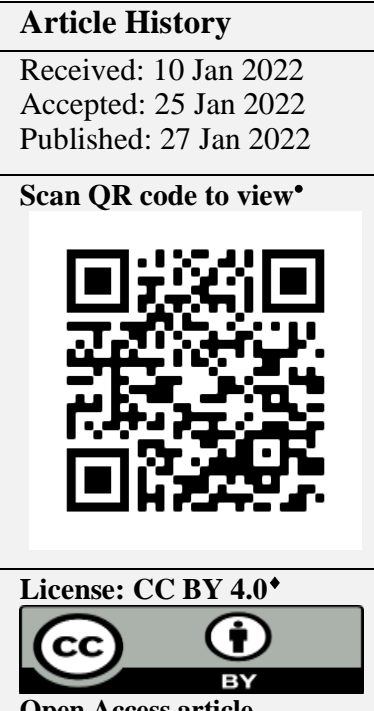

Open Access article.

How to cite this paper: Olisah, M.C., Meludu, S.C. and Dioka C.E. (2022). Effect of Formaldehyde Exposure on Oxidative Stress Markers, Liver and Kidneys of Medical Students during Dissection in Gross Anatomy Laboratory. Scicom J Med Appl Med Sci, 1(1), 19-23. https://doi.org/10.54117/sjmams.v1i1.4

\section{Introduction}

Formaldehyde was discovered in 1867 by the British chemist, August Wilhelm von Hofmann. It is a simple aldehyde with the molecular formula $\mathrm{CH}_{2} \mathrm{O}$. At room temperature, it is a colourless gas, has flammable properties and irritating repugnant odour (IARC, 2006). Formalin is an aqueous form of formaldehyde, containing $37 \%$ by weight or $40 \%$ by volume of formaldehyde gas in water. It is the chemical most commonly used for embalmment (Raja, 2012). Occupational exposure to formaldehyde is a public health problem with a large number of adverse 
effects underreported (Solomon et al., 2021). The chemical is mainly used to preserve cadavers in anatomy dissecting laboratories and most mortuaries. During embalmment, formaldehyde is introduced as a fixative in the body tissues of cadavers. This helps to preserve the cadaver by maintaining, as far as possible, a life-like state, and in the process, retaining the normal anatomical relations as are required for dissection purposes (Girish et al., 2014; Roland et al., 2019). Thus anatomists, technicians in biological science laboratories, morticians in embalming centres and medical school students in dissection hall are regularly exposed to formaldehyde (Noha Selim et al., 2019). Liver injury has long been associated with occupational exposure to a wide variety of chemicals. Its susceptibility to chemical injury is a result of its unique position within the circulatory system, and also because it is the primary organ for the biotransformation of chemicals within the body (Osadolor et al., 2014), as the liver is the main organ involved in the metabolism of toxins and medicinal agents. Reactive oxygen species (ROS) are formed in cells through the reduction of oxygen by biological reducing agents, with the catalytic assistance of electron transfer enzymes and redox-active chemical species such as redox-active organic chemicals and metals (Ntziachristos et al., 2007). In the area of endogenous antioxidant defences, excess amount of ROS leads to the depletion of the protective antioxidants, superoxide dismutase (SOD) and glutathione (GSH) (Kariola et al., 2006). A decrease in the protective mechanisms by these antioxidants will lead to oxidative stress with pathological consequences (Abd Ellah et al., 2007). Some trace elements; such as zinc, has been proved to have hepato-protective properties as they serve as cofactors to some antioxidant enzymes

In the past few decades, organic solvent like formaldehyde has become an increasing potential health hazard because of its widespread use in the preservation of cadavers in mortuaries, fixatives in many laboratories The use of formaldehyde solutions as a fixative in embalming centres or mortuaries is a common practice, most especially for the developing countries where infrastructures are often inadequate, couple with the unstable supply of electricity. Sound anatomical knowledge and dissection of the human body remain the cornerstone of medical students in their medical curriculum. Exposure to formaldehyde in the department of anatomy is continuous and higher than its use in other medical laboratories (Onyije et al., 2012). This causes an increase in formaldehyde inhalation in people. Hence the anatomy dissection laboratory and mortuaries represent a significant domain of contact and exposure. Chronic formaldehyde inhalation may deplete the activities of antioxidant enzymes, stimulate oxidative stress and thus causes vital organ toxicity (Euphoria et al., 2014 and Ramos et al., 2017). Many researchers, (Binawara et al., 2010; Jain et al., 2012 and Onyije et al., 2012) reported only physical signs and symptoms of exposure to formaldehyde in medical students, there is little or no available data on the biochemical changes in medical students exposed to formaldehyde.

\section{Methodology}

A descriptive, cross-sectional study was carried out among undergraduate students. The study included the total class population of the 2017 set of medical students (56 male students) from the College of Medicine, Chukwuemeka Odumegwu Ojukwu University, Uli. Female students were excluded from this study because the profession is predominantly male morticians and also possible menstrual cycle interferences. These students were recruited immediately after first year, that is, before the commencement of dissection. After verbal consent, a detailed personal, and medical questionnaire was completed by the students through personal interviews. These students were monitored to ensure compliance with the use of the class attendance sheet. The average duration of exposure for each student in the dissection hall was $6 \mathrm{hrs}$./week. Baseline samples were collected before exposure to formaldehyde. Subsequent samples were collected at one month, three and six-month intervals. All samples were collected immediately after dissection at the required period. The dissection periods are two times per week each lasting for 3hours (1-4 pm).

\section{Exclusion Criteria}

Students with a history of viral hepatitis, recent blood transfusion, or hospitalization for major surgery and chronic alcohol consumers were excluded from the study. Direct entry students who read Anatomy and other basic medical sciences who were exposed to formaldehyde during their first degree.

\section{Samples Collection and Assay}

Eight millilitres $(8 \mathrm{ml})$ of fasting blood samples were collected from all subjects by sterile disposable syringes into a sterile plain container and allowed to clot, retracted and centrifuge at 3000 r.p.m for 10 minutes. Thereafter, serum was separated into two aliquots. One part of the samples was stored at $-20{ }^{\circ} \mathrm{C}$ for analysis of oxidative stress markers (GPx, SOD and MDA) within two weeks of collection, while the remaining aliquot was stored at $-20{ }^{\circ} \mathrm{C}$ and used for the analysis of liver and kidney markers. The analysis was done at Chemical Pathology Department, Nnamdi Azikiwe University Teaching Hospital Nnewi.

Ethical Approval

Ethical approval was obtained from the ethics committee of Nnamdi Azikiwe University Teaching Hospital Nnewi. NAUTH/CS/66/VOL.11/023/2018/023.

\section{Statistical Analysis}

The collected data and the laboratory results were computed. Statistical analysis was done. The quantitative results were expressed as means \pm standard deviation (SD). Paired t-test was employed using SPSS version 21 in the analysis of data. P values $<0.05$ were considered significant.

\section{Results}

The oxidative stress markers were assessed in medical students who were exposed to formaldehyde 6 hours per week during their training in the anatomy dissecting hall. The result showed that Glutathione peroxidase and superoxide dismutase (SOD) activities were significantly reduced after one and three-month periodic exposures when compared with the baseline study (Table 1). However, there is no significant difference when the baseline study was compared with three and six-month exposures Malondialdehyde (MDA) level was significantly lower when the baseline study was compared with the one month and three-month exposure but does not differ significantly from that of six-month exposures (Table 1). Also, when one-month exposure was compared with six-month exposures, it was statistically significant. The trace metals (Se and $\mathrm{Zn}$ ) were statistically significant when the baseline study was compared with that of one and three-month exposures. Moreover, the level of Zinc was significant when the baseline study was compared with the six-month exposures (Table 1).

The activity of ALT was significantly higher after one and three-month periodic exposures when compared with the baseline study. Also, when one-month exposure was compared with six-month exposures, it was statistically significant. However, when the baseline study (A) was compared with six-month exposures, it was not significant. When the activities of AST, ALP and other liver markers which include albumin, $\mathrm{AFP}$, total protein, conjugated and unconjugated bilirubin of baseline study were compared with the one, three and six-month periodic exposures, it was not statistically significant across all groups (Table 2). When the concentrations of the serum electrolytes of the baseline study were compared with one, three and six-month periodic exposures, it was not statistically significant. Also, the level of creatinine and cystatin C were found to be insignificant when the baseline survey was compared with the one, three and six-month exposures. However, the concentration of urea was found to be significant when one-month periodic exposures were compared with the baseline study. Also, when the baseline studies were compared with three and six-month exposures it was not statistically significant (Table 3)

\section{Discussion}

Globally, medical education is rigorous, expensive and full of challenges. Environmental challenges such as exposure to formalin inhalation during dissecting sessions have not been adequately addressed. Medical students are routinely exposed to formaldehyde during their dissecting practical classes. A thorough dissection of the human body remains the prerequisite of their medical training. 
Table 1: The oxidative stress markers of students exposed to formaldehyde at different time intervals (Mean \pm SD).

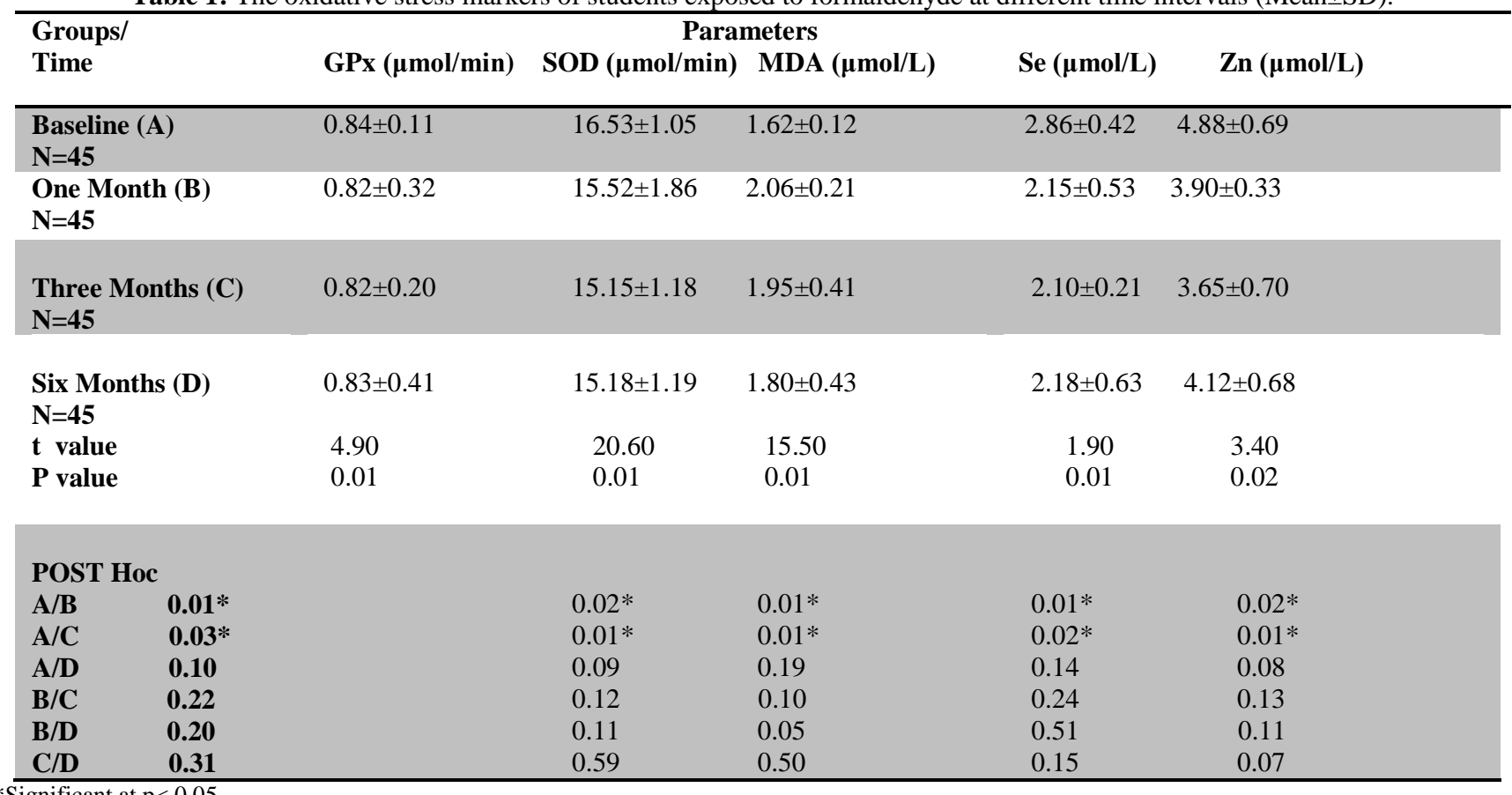

*Significant at $\mathrm{p}<0.05$

Table 2: The liver markers of students exposed to formaldehyde at different periods (Mean \pm SD).

\section{Parameter}

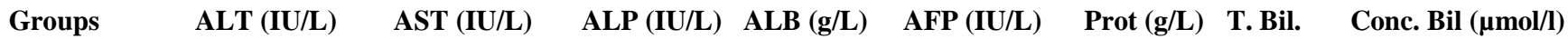

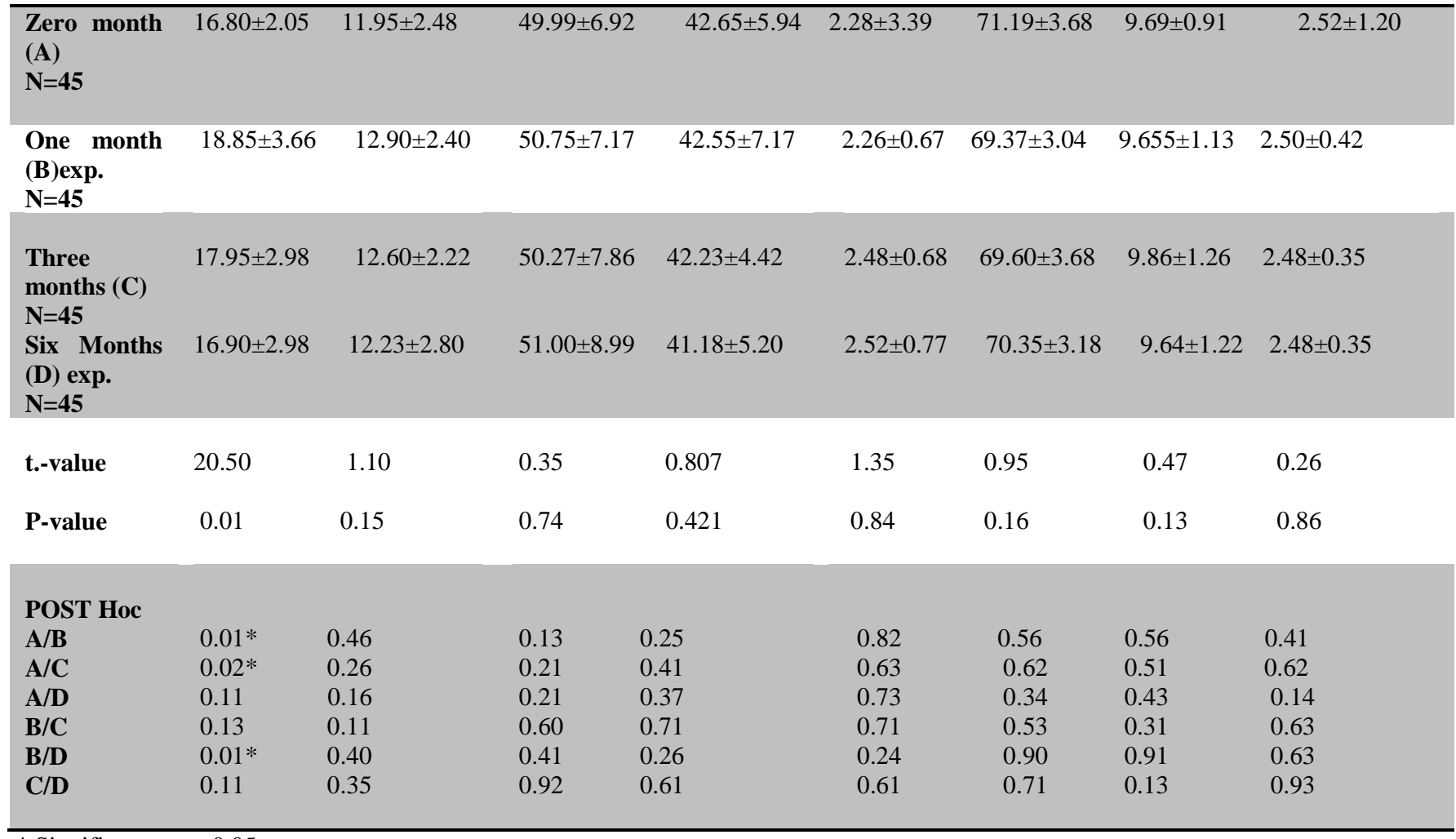

* Significant at $\mathrm{p}<0.05$ 
Table 3: The kidney markers of students exposed to formaldehyde at different periods (Mean \pm SD).

\begin{tabular}{|c|c|c|c|c|c|c|}
\hline Groups & $\mathrm{Na}^{+}(\mathbf{m m o l} / \mathrm{L})$ & $\mathrm{K}^{+}(\mathbf{m m o l} / \mathbf{L})$ & $\begin{array}{c}\text { Parameter } \\
\mathrm{Cl}^{-}(\mathrm{mmol} / \mathrm{L}) \\
\mathrm{HCO}_{3}^{-}(\mathrm{mmol} / \mathrm{L})\end{array}$ & Urea $(\mathrm{mmol} / \mathrm{L})$ & $\operatorname{Creat}(\mu \mathrm{nol} / \mathrm{L})$ & Cyst C(ng/dl) \\
\hline $\begin{array}{l}\text { Zero month } \\
\text { (A) } \\
\mathrm{N}=45\end{array}$ & $143.42 \pm 2.48$ & $3.47 \pm 0.31$ & $101.37 \pm 3.86 \quad 23.70 \pm 1.82$ & $3.22 \pm 0.28$ & $74.50 \pm 12.04$ & $192.96 \pm 13.07$ \\
\hline $\begin{array}{l}\text { One month } \\
\text { (B) expt. } \\
\mathrm{N}=45\end{array}$ & $142.81 \pm 2.66$ & $3.94 \pm 0.39$ & $101.59 \pm 3.45 \quad 24.00 \pm 1.72$ & $3.95 \pm 0.84$ & $78.53 \pm 9.19$ & $193.99 \pm 13.76$ \\
\hline
\end{tabular}

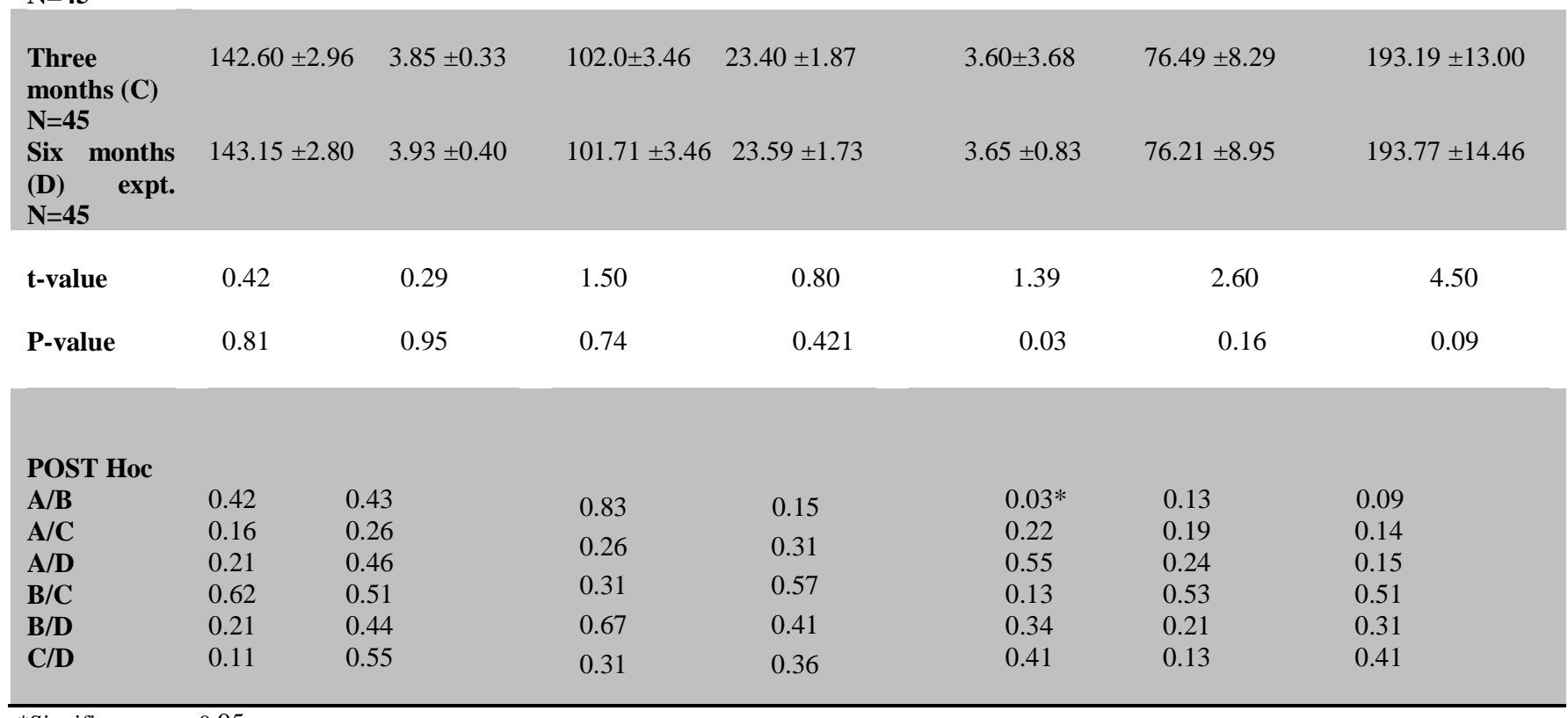

*Significant at $\mathrm{p}<0.05$

In our study, the activities of antioxidant enzymes- GPx and SOD among medical students were decreased initially after one-month exposure to formaldehyde but later increased after six months of exposure. One would expect a continuous decline in antioxidant enzymes but the scenario was different. The possible explanation to this finding could be that initial exposure to formaldehyde may cause alterations in cellular metabolisms resulting in the generation of ROS which led to oxidative stress within one month of initial exposures. To cope with the situation, there was an increase in demand for the enzyme activity which led to its decline in the activity of antioxidant enzymes.

However, there is a cellular adaptation to this oxidative stress which led to maintaining the normalcy of the cellular functions after subsequent exposures at three and six month periods.

The levels of the MDA were also increased after one month of exposure but gradually decreased after three and six-month exposures. The possible reason could also be that of cellular adaptation and that the subsequent exposures were not enough to generate much higher ROS to increase the MDA levels. The trace elements (Se and $\mathrm{Zn}$ ) were observed to vary with their corresponding antioxidant enzymes. There is a scarcity of information on oxidative stress markers in students exposed to formaldehyde to compare with this study. Other reports suggestive of the significant effect of formaldehyde on oxidative stress markers were those observed in morticians as reported by Osadolor et al. (2014), Euphoria et al. (2015) and Olisah et al. (2017).

Hence this study was aimed at estimating some biochemical parameters in these students to ascertain possible vital organ toxicities. We observed that the AST was significantly raised after one month of periodic exposures among the medical students. It was however, observed that the level was decreasing as time progresses. Alanine transferase enzyme is a cytosolic enzyme that is usually the first to be released into the plasma in acute hepatic injuries. The initial rise after first exposure could be attributed to the primary response by the hepatic cells in response to the ROS generated by formaldehyde exposures. Secondly, the initial exposure after one month may have triggered some inflammatory reactions through generations of ROS which later was curtailed by some form of cellular adaptations. The gradual decline in the level after 3 and
6 months could be a result of cellular adaptation and secondly, the rate of exposure may not be sufficient to cause further damage to the hepatocytes. The activity of aspartate transaminase which is both cytosolic and mitochondrial enzyme is increased in chronic illness or hepatocellular necrosis. These enzymes were not markedly raised across the period of study because the rate and duration of exposure may not be severe to cause toxicities to the hepatocytes as compared with that observed in morticians in studies done by Euphoria et al. (2015) and Olisah et al. (2020).

Moreover, the mean levels of ALP and AFP were not raised across all groups during exposures. Though the mean concentrations of total protein and albumin were reduced as time were progressing, it was however, not significant when compared with the baseline studies This study, however, differ from the study done by Ihim et al. (2017) who observed a significant change in total protein and albumin among medical students exposed to formaldehyde. The interpretation may be that the duration of exposures and concentration of inhaled formaldehyde may not be enough to have caused a severe hepatic injury. The levels of conjugated and total bilirubin do not vary essentially when the baseline exposures were compared with one month, three and six-month exposures.

There were no electrolyte and creatinine derangements in students exposed to formaldehyde during the periods of dissections. The mild elevation of urea after one month of dissection may be a result of the initial dehydrating effect of formaldehyde.

Surprisingly, the mean serum creatinine level in our study does not differ significantly across the periods of exposure when compared with the baseline study. Serum creatinine is much less affected by these extra-renal factors as it depends majorly on the muscle mass and body weight (Carl et al., 2008, Olisah et al., 2021) and this perhaps explains why its level remained the same throughout the periods of exposure in the phase of an increasing urea level. Importantly, in situations where pre-renal factors affect the level of serum urea; the serum creatinine level may be normal (Carl et al., 2008; Kamal, 2014; Suresh et al., 2014). These results of an increase in the level of urea agree with the study done by Ihim et al.,2017 on medical students exposed to formaldehyde but differ in levels of electrolytes which were observed to be increased among the medical students exposed to formaldehyde over a short period. 
The mechanism behind these insignificance results in the mean serum electrolyte and cystatin $\mathrm{C}$ levels over the periods of formaldehyde exposures in students observed in our study remains unclear to us. Perhaps, the dehydration effect due to formaldehyde inhalation might not be enough to cause nephrotoxicity or the concentration/ duration of exposure may not have been enough that could lead to alterations in osmolarity. Hence, formaldehyde may induce a temporary hemoconcentration in subjects resulting in the elevation of urea level in the serum. Secondly, as earlier pointed out, the insignificant changes at three and six-month periods could also be some form of cellular adaptation. There is no derangement in cystatin $\mathrm{C}$ levels among the student. One of the reasons as mentioned earlier may be that the duration and concentrations of formaldehyde inhaled may not be sufficient to cause renal impairment.

\section{Conclusion}

The current study highlighted the adverse effect of formalintreated cadavers on medical students. This is probably, among the few studie dealing with some biochemical effects of formaldehyde in medical students who were exposed during their training in the Anatomy dissecting hall Formaldehyde may cause deleterious effects in vital organs through the direct effect or indirectly by the generation of reactive oxygen species which led to oxidative stress. The oxidative stress exerted in these vital organs may lead to cellular injuries with ultimate cell dead. The study has shown that formaldehyde exposures during medical training may not cause significant damage to tissues. Apart from the mild discomfort from the irritation of the eyes, upper airways and skin, there is no clear evidence that formaldehyde induces cellular damage in the vital organs of the students within the shor period of exposure. Perhaps, the concentration and duration of exposures may not be enough to cause any vital organ toxicities.

\section{References}

Abd Ellah, M.R., Okada, K and Yasuda, J. (2007). Oxidative stress and bovine liver diseases: Role of glutathione peroxidase and glucose 6-phosphate dehydrogenase. Japanese Journal of Veterinary Research. 54(4):163-173.

Agency for Toxic Substances and Disease Registry (ATSDR). (2020). Toxicological Profile for $\quad$ Formaldehyde. https://www.atsdr.cdc.gov/toxprofiles/tp111.

Akwiwu, E. C., Usoro, C. A.O., Akpotuzor, J. O., Etukudo, M. H. (2015) Occupational Health and the Impact of Long Term Formaldehyde Exposure on Health Professionals in Calabar, Nigeria. Journal of Natural Sciences Research: 5, 119-126.

Araoye, M.O. (2003). Research Methodology with statistics for Health and Social Sciences. 1st

Binawara, B.K., Rajnee, A.D., Choudhary, S., Mathur, K.C., Sharma, H. and Goyal, K. (2010). Acute Effect of formalin on pulmonary function tests in Medical Students. Pakistan Journal Physiol. 6(2).

Committee for Risk Assessment (RAC). (2012). Proposing Harmonised Classification and Labelling at EU Level of Formaldehyde. The European Chemicals Agency (ECHA), Helsinki.

Dixit, D. (2008). Role of standardized embalming fluid in reducing the toxic effects of formaldehyde. Indian Journal of Forensic Medical Toxicology. 2:10061012.

Driscoll, T.R., Carey, R.N., Peters, S. Glass, C.D., Benke, G., Reid, A. and Fritch, L. (2015). The Australian work Exposure study: Prevalence of occupational exposure to formaldehyde. Annals of Occupational Hygiene. 60(1):132-138. https://doi.org/10.1093/annhyg/mev058

Egwurugwu, J.N., Ohamaeme, M.C., Izunwanne, D., Ugwuezumba, P.C., Ngwu, E.E., Elendu, M.U., Nwamkpa P. and Ekweogu C.N. (2018). Assessment of the Inhalational Effects of Formalin on the lipid profile of Wistar Albino rats. Research Journal in Health Sciences. 3:

Emue, B.E., Ayanniyi, A.A., Nwegbu, M.M. and Ibekwe T.S. (2011). Acute effects of formalin treated cadaver on Nigerian medical students. American Journal of Tropical Medicine and Public Health. 1:89-96.

Girish, V.P., Shishirkumar, S., Thejeshwari, T. and Apoorva D. (2014). Physical Reactions of Formalin used as Cadaver Preservative on First Year Medical Students. Journal of Evidence Based Medicine and Healthcare. 1(5):279-283. https://doi.org/10.18410/jebmh/2014/44

Ihim, A.C., Ogbodo, E.C., Oguaka, V.W., Ozuruoke, D.F.N., Okwara, E.C. Nwovu, A.I., Amah, U.K. and Abiodun, B.E. (2017). Effect of short term exposure to formalin on kidney function tests of students in Nnewi. European Journal of Biomedical and Pharmaceutical Sciences. 4(12):51-55.
International Agency for the Research on Cancer (IARC). (2012). Formaldehyde, A Review of Human Carcinogens: Chemical Agents and Related Occupations: Lyon.

Jain S.R., Nahar P.S. and Baig M.M. (2012). Study of Formalin Toxicity in I MBBS Students. International Journal of Science and Research.

Kaliora A.C., Dedoussis G.V. and Schmidt H. (2006). Dietary antioxidants in preventing atherogenesis. Atherosclerosis. 187:1-17. https://doi.org/10.1016/j.atherosclerosis.2005.11.001

Kim, K.S., Yang, H.Y., Song, H., Kang Y.R., Kwon, J., An, J., Son, J.Y., Kwack, S.J., Kim, Y.M., Bae, O.N. (2017). Identification of a sensitive urinary biomarker, selenium binding protein 1, for early detection of acute kidney injury. Journal of Toxicology \& Environmental Health. 80:453-464. https://doi.org/10.1080/15287394.2017.1299655

Murty, M .S .N, Sharma, U. K., Pandey, V .B., Kankare, S B (2013. Serum cystatin $\mathrm{C}$ as a marker of renal function in detection of early acute kidney injury. Indian Journal Nephrology; 23(3): 180-3. https://doi.org/10.4103/0971-4065.111840

Ntziachristos, L., J.R. Froines, A.K Cho and C. Sioutas, (2007). Relationship between redox activity and chemical speciation of size-fractionated particulate matter Particle and Fibre Toxicology., 4:5-10. https://doi.org/10.1186/1743-8977-4-5

Olisah, M.C, Meludu S.C., Dioka C.E. (2021). A Comparative Study of Serum Cystatin C, Serum Electrolytes, Urea and Creatinine in Early Detection of Kidney Injuries in Albino Rats Exposed to Formaldehyde. IPS Journal of Toxicology. 1(1): 1-4 Doi: Https://Doi.Org/10.54117/Ijt.V1i1.1.2021 https://doi.org/10.54117/ijt.v1i1.1.2021

Olisah, M.C., Meludu S.C., Dioka C.E., Egbuna, C.and Onyekere P. F. (2020) Oxidative Stress Markers and Liver Functions of Morticians Exposed to Formaldehyde in South-Eastern, Nigeria. IOSR Journal of Environmental Science, Toxicology and Food Technology. 14:3:Pp 14-18

Olisah, MC, Ifemeje. J.C, Ilechukwu OU, Ofor CC. (2017). Effect of formaldehyde inhalation and alcohol consumption on some kidney markers of Albino rats. Tropical Journal of Applied Natural Sciences, 2(1):98- 101. https://doi.org/10.25240/TJANS.2017.2.1.16 https://doi.org/10.25240/TJANS.2017.2.1.16

Onyije, FM, Avwioro O.G. (2012). Excruciating effects of formaldehyde exposure to students in gross anatomy dissection laboratory. The International Journal of Occupational and Environmental Medicine; 3:92-95.

Osadolor, H. B., Igharo, O. G., Ilyas, Y. Igharo, L. E. ( 2014).Study of Antioxidant Status in Morticians Exposed to Formaldehyde in Benin City, Nigeria. Annals of Biomedical Sciences. 13: 2-9.

Raja, D.S. (2012). Potential health hazards for students exposed to formaldehyde in the gross anatomy laboratory. Journal Environmental Health. 74: 36-40.

Ramos, C.O., Nardeli C.R., Campos K.K.D., Pena K.B., Machado D.F., Bandeira A.C.B., Costa, G.P., Talvani, A, Bezerra, F.S. (2017). The exposure to formaldehyde causes renal dysfunction, inflammation and redox imbalance in rats. Experimental and Toxicologic Pathology.; 69:367-372. https://doi.org/10.1016/j.etp.2017.02.008

Roland, O.W., Douglas, K.E. and Akaranta, O. (2019). Comparative Assessment of Formaldehyde Concentrations in Public and Private Mortuaries in Rivers State, Nigeria. Journal of Scientific Research \& Reports, 23, 1-11. https://doi.org/10.9734/jsrr/2019/v23i230115

Solomon, T., Niguse H, Asfaw G and Zenebe N. (2021). Occupational formaldehyde exposure linked to increased systemic health impairments and counteracting beneficial effects of selected antioxidants. Alexandria Journal of $\quad$ Medicine. $57: 1.157-167$. https://doi.org/10.1080/20905068.2021.1926172

Uboh, F.E., Ebong PE. Eka,OU, EU Eyong, EU Akpanabiatu.MI. (2005). Effect of inhalation exposure to kerosene and petrol-fumes on some anaemia-diagnostic indices in rats Global Journal of Environmental Sciences. 4 (1): 59-63. https://doi.org/10.4314/gjes.v4i1.2442

World Health Organisation (2017). WHO guidelines for indoor air quality: selected pollutants.

Zararsiz, I., Sonmez, M.F., Yilmaz, H.R., Tas, U., Kus, I., Kavakli, A., Sarsilmaz, M. (2006). Effects of omega-3 essential fatty acids against formaldehydeinduced nephropathy in rats. Toxicology Industrial. Health. 22(5):223-9. https://doi.org/10.1191/0748233706th260oa

Zemba, S., Damiano, L., Little, H., Doris, J., and Estabrooks M. (2019). Formaldehyde A Leading Air Toxic The Magazine for Environmental Managers. Pp: 5-12.

- Thank you for publishing with us. 